\title{
INTERPRETIVE SUMMARIES, JULY 2015
}

Increasing stringiness of low-fat mozzarella string cheese using polysaccharides. By Oberg et al., page 4243. Mozzarella string cheese is growing in popularity as a snacking cheese, and manufacturing lower fat versions causes cheese stringiness to be lost. To mimic fat's function in creating channels between strands of proteins during the cooking and stretching process, we mixed hot slurries of starches and gums into hot low-fat cheese and then extruded it to form string cheese. Xanthan gum functioned best in creating stringiness in a low-fat mozzarella cheese although the low-fat string cheeses softened during 8 wk of storage, with much of the initial stringiness lost.

http://dx.doi.org/10.3168/jds.2014-8733.

Prevalence of enterotoxin genes and antimicrobial resistance of coagulase-positive staphylococci recovered from raw cow milk. By Rola et al., page 4273. Staphylococci are common microorganisms present on the skin and mucosal surfaces of humans and animals as well as in the environment. Raw milk may be contaminated by enterotoxigenic coagulase-positive staphylococci. Several of these microorganisms show antimicrobial resistance. Consumption of raw cow milk contaminated with such pathogens may be a public health threat. The aim of the study was to determine the prevalence of enterotoxin genes and antimicrobial resistance in coagulase-positive staphylococci isolated from raw cow milk in Poland.

http://dx.doi.org/10.3168/jds.2014-9064.

Carbon footprint of dairy goat milk production in New Zealand. By Robertson et al., page 4279. The aim of this study was to assess the cradle-to-farm gate carbon footprint of indoor and outdoor dairy goat milk production systems in New Zealand, identifying issues related to methodology, variability, and carbon footprint hotspots. The study will allow dairy goat milk producers to better understand the major factors contributing to the carbon footprint and the effect of management decisions, and to identify strategies to reduce the carbon footprint.

http://dx.doi.org/10.3168/jds.2014-9104.

Microbiological quality of milk sold directly from producers to consumers. By Pyz-Lukasik et al., page 4294. We determined microbial quality of raw cow milk offered to customers at direct sale points. Milk samples were evaluated in terms of total bacterial count per milliliter, as well as for potentially pathogenic bacteria presence and count. Presence of antibiotics and inhibitory substances and somatic cell count were also determined. The performed investigations compared quality of the examined milk samples to the regulatory standards for European Union countries, and revealed milking hygiene conditions and mammary gland health status of cows from which the milk samples were collected. Potential consumer health hazards were indicated.

http://dx.doi.org/10.3168/jds.2014-9187.

Microbiological shelf-life at different temperatures and fate of Listeria monocytogenes and Escherichia coli inoculated in unflavored and strawberry yogurts. By Tirloni et al., page 4318. Three trials were performed in artisanal unflavored and strawberry yogurts. In trial 1, unflavored and strawberry yogurts showed low microbial loads at $4^{\circ} \mathrm{C}$, with yeasts that were shown to be specific spoilage organisms of unflavored and strawberry yogurts. In trial 2, Escherichia coli and Listeria monocytogenes added at 2 concentrations (2 and $5 \log \mathrm{cfu} / \mathrm{g}$ ) showed a rapid decrease because of the acidic conditions of the products. In trial 3 , no differences in the fate of wild and acid-adapted strains of L. monocytogenes were observed in the yogurt due to the rapid adaptation after inoculation.

http://dx.doi.org/10.3168/jds.2015-9391.

Kinetic and thermodynamic parameters for thermal denaturation of ovine milk lactoferrin determined by its loss of immunoreactivity. $B y$ Navarro et al., page 4328. Lactoferrin is a milk protein with important biological activities. It can be obtained from some dairy by-products and has potential applications in nutraceutical foods. In this study, we evaluated the effect of several heat treatments on ovine milk lactoferrin. Denaturation of lactoferrin was estimated by measuring its reactivity against specific antibodies and by analyzing variation in hydrophobicity. The kinetic and thermodynamic parameters obtained for the denaturation process of ovine lactoferrin allowed us to identify heat treatments that can preserve its integrity and biological activity.

http://dx.doi.org/10.3168/jds.2015-9403.

Different management practices are associated with mesophilic and thermophilic spore levels in bulk tank raw milk. By Miller et al., page 4338. The potential influence of management practices on raw milk spore level is poorly understood. We examined bulk tank raw milk samples from 33 farms for levels of psychrotolerant, mesophilic, and thermophilic spores. Overall, psychrotolerant spores were rarely detected, and different management practices were associated with mesophilic and thermophilic spore levels. These results provide important baseline data regarding spore levels in bulk tank raw milk and suggest that different strategies may be necessary to reduce contamination of raw milk with different spore types.

http://dx.doi.org/10.3168/jds.2015-9406. 
Effects of nisin on Staphylococcus aureus count and physicochemical properties of Minas Frescal cheese. By Felicio et al., page 4364. Minas Frescal cheese is widely consumed in Brazil. It is a high pH and moisture cheese, and it can be contaminated with many spoilage and pathogenic bacteria. Staphylococcus aureus can be found in high numbers in Minas Frescal cheese because of extensive handling during production. In this work, nisin was used to control cheese contamination. We found that nisin was effective in reducing the bacterial count in milk and in cheese. Nisin has potential to be used as a hurdle to improve Minas Frescal cheese safety without replacing good manufacturing practices. http://dx.doi.org/10.3168/jds.2015-9520.

Short communication: Determination of withdrawal time for oxytetracycline in different types of goats for milk consumption. By Attaie et al., page 4370. Presence of oxytetracycline in milk above $300 \mathrm{ng} / \mathrm{mL}$ is a health hazard. The objective of this study was to determine the withdrawal period of lactating goats and residual amounts of oxytetracycline in fresh, aged, and pasteurized milks. Our results indicated that oxytetracycline is not stable in milk at refrigeration temperature or during pasteurization and will decrease significantly. The withdrawal period for oxytetracycline in lactating goats is $72 \mathrm{~h}$, which is shorter than the 96-h withdrawal period that has been used for lactating cows. This study provides useful information to goat milk producers and regulatory agencies in their daily practices.

http://dx.doi.org/10.3168/jds.2014-8616.

Short communication: Latin-style fresh cheese enhances lactic acid bacteria survival but not Listeria monocytogenes resistance under in vitro simulated gastrointestinal conditions. By Silva et al., page 437\%. In order to exert their beneficial effect, probiotic strains must maintain good viability in the harsh conditions of the gastrointestinal transit (GIT). Therefore, resistance to human GIT conditions is an important factor for the selection of new probiotics. In this study, the acidic conditions and the presence of bile salts and digestive enzymes were tested on the survival of 28 lactic acid bacteria (LAB) strains and Listeria monocytogenes. Overall, LAB showed poor resistance to gastric acidity, but when included in Latin-style fresh cheese, their survival was greatly improved. In contrast, Listeria monocytogenes in cheese showed poor resistance to acidic conditions.

http://dx.doi.org/10.3168/jds.2015-9420.

Technical note: A portable on-chip assay system for absorbance and plasmonic detection of protein hormone in milk. By Ozhikandathil et al., page 4384. We describe the development of a low-cost microfluidic chip integrated into a portable device that could allow rapid testing of the presence and amount of hormones in milk. The method of detection and quantification is simple and can be performed in the field without the need for specialized training. http://dx.doi.org/10.3168/jds.2014-8934.

Effect of recombinant bovine somatotropin administration on health and performance of lactating dairy cows diagnosed with hyperketonemia. By Gohary et al., page 4392. Monitoring fresh dairy cows for early diagnosis and treatment of postpartum diseases is a common practice in many dairy herds. A large clinical trial was conducted to evaluate the effect of administration of recombinant bovine somatotropin (rbST) as a potential treatment for lactating dairy cows diagnosed with hyperketonemia. Administering rbST to cows with hyperketonemia did not enhance health, production, or reproductive parameters. Therefore, it is not recommended to use a low dose of rbST as therapy for cows with hyperketonemia.

http://dx.doi.org/10.3168/jds.2014-8235.

Cow- and herd-level risk factors for on-farm mortality in Midwest US dairy herds. By Shahid et al., page 4401. The objectives of this study were to describe on-farm mortality and to investigate cow- and herd-level risk factors associated with mortality in Midwest US dairy herds. We found that more cows died in early lactation, and mortality was lower for cows with greater first test-day milk yield. Mortality hazard was greater in larger herds and lower in herds with higher average milk production. First test-day milk yield could be helpful to identify cows at higher risk for mortality, and quality management in the transition period would be useful to reduce mortality rate in dairy herds. http://dx.doi.org/10.3168/jds.2014-8513.

Relationship of concentrations of cortisol in hair with health, biomarkers in blood, and reproductive status in dairy cows. By Burnett et al., page 4414. Hair cortisol has been used to measure chronic stress in several species. In dairy cows, the use of hair as the tissue of choice for cortisol measurement offers the advantage of being noninvasive, fast, and able to indicate levels of cortisol over long periods. Multiparous cows that became pregnant by 100 days postpartum had lower concentrations of hair cortisol at 42 and $84 \mathrm{~d}$ in milk. Hair cortisol concentration was greater if samples were collected after a cow was affected by clinical disease but was unaffected when subclinical endometritis was observed.

http://dx.doi.org/10.3168.jds.2014-8871.

Minimum inhibitory concentrations of selected antimicrobials against Escherichia coli and Trueperella pyogenes of bovine uterine origin. By de Boer et al., page 442\%. Minimum inhibitory 
concentrations (MIC) of 9 antimicrobials for isolates of 2 common bovine intrauterine bacterial pathogens (Escherichia coli and Trueperella pyogenes) were determined. Potential antimicrobial resistance was observed for some of the antimicrobials tested for $E$. coli or $T$. pyogenes. Isolation of $E$. coli with an $\mathrm{MIC} \geq 8 \mu \mathrm{g} / \mathrm{mL}$ of oxytetracycline at $23 \mathrm{~d}$ postpartum was associated with a lower probability of pregnancy within 6 wk of commencement of breeding compared with those isolates having an MIC $<8 \mu \mathrm{g} / \mathrm{mL}$. Further studies are required to define interpretative criteria, including determination of pharmacokinetic and pharmacodynamic profiles for veterinary antimicrobials.

http://dx.doi.org/10.3168/jds.2014-8890.

Milk yield differences between $1 \times$ and $4 \times$ milking are associated with changes in mammary mitochondrial number and milk protein gene expression, but not mammary cell apoptosis or SOCS gene expression. By Alex et al., page 4439. Milk yield differences between $1 \times$ and $4 \times$ milking are associated with changes in mammary mitochondrial number and milk protein gene expression but not mammary cell apoptosis or suppressors of cytokine signaling (SOCS) gene expression. Small animal numbers and somatic cell content of milk used for gene expression may have contributed to our inability to detect differences in $S O C S$ gene expression.

http://dx.doi.org/10.3168/jds.2014-8917.

Effects of recombinant bovine somatotropin during the periparturient period on innate and adaptive immune responses, systemic inflammation, and metabolism of dairy cows. By Silva et al., page 4449. Excessive body condition score during the prepartum period has been associated with immunosuppression and health disorders in dairy cows. The current experiment evaluated the effects of recombinant bovine somatotropin (rbST) treatment of dairy cows during the periparturient period on immune responses, systemic inflammation, and metabolism. Treatment with rbST increased concentrations of growth hormone and insulin-like growth factor 1. Intensity of phagocytosis and oxidative burst by polymorphonuclear cells and the concentration of immunoglobulin $\mathrm{G}$ anti-ovalbumin were increased by rbST treatment during the prepartum period. Metabolic parameters were minimally affected but metritis incidence was reduced in cows treated with rbST. Treatment of dairy cows with rbST during the transition period may be an alternative to improve immune function and reduce the risk of postparturient diseases.

http://dx.doi.org/10.3168/jds.2014-8959.

Rear shape in 3 dimensions summarized by principal component analysis is a good predictor of body condition score in Holstein dairy cows. By
Fischer et al., page 4465. Body condition assesses the level of body reserves. Body reserves are highly mobilized in early lactation to produce milk and indirectly associated with health and reproductive performance. The consideration of body reserves is important in dairy production but is not easy to monitor. Body condition is therefore an interesting trait but it needs objective and more precise phenotyping than the commonly used body condition score (BCS). The project developed an efficient estimation of BCS from 3-dimensional surfaces of the rear of dairy cows. This innovative method could easily be adapted to other scales and, after being fully automated, will become available for broadband use. http://dx.doi.org/10.3168/jds.2014-8969.

Evaluation of treatments for claw horn lesions in dairy cows in a randomized controlled trial. By Thomas et al., page 447\%. Lameness in dairy cows is a significant health and welfare problem around the world. Diseases affecting the hoof are some of the most common problems. Thousands of animals are treated for these conditions, yet there is little research evidence on the most effective treatments. We tested 4 treatments in an on-farm trial: a therapeutic trim alone or in combination with either elevating the diseased digit using a glue on block or a course of antiinflammatories or both additional treatments. The combination of trimming, elevation of the claw, and course of antiinflammatories was most successful. We recommend its use on-farm.

http://dx.doi.org/10.3168/jds.2014-8982.

First-lactation performance in cows affected by digital dermatitis during the rearing period. $B y$ Gomez et al., page 4487. A study was performed to evaluate first-lactation performance in cows affected with digital dermatitis (DD) during a period of 6 mo before first calving. Heifers diagnosed with repeated cases of DD during the rearing period showed increased days to conception and decreased conception rates at first insemination. All heifers diagnosed with DD before calving showed significantly less milk production and increased number of DD events during the first lactation. Successful DD control programs should focus their attention on the period before calving.

http://dx.doi.org/10.3168/jds.2014-9041.

Essential amino acid infusions stimulate mammary expression of eukaryotic initiation factor $2 \mathrm{~B} \varepsilon$ but milk protein yield is not increased during an imbalance. By Doelman et al., page 4499. Essential amino acid supply has been shown to influence milk protein yield in lactating dairy cows. To determine the effect on production and the molecular pathways that are thought to control protein synthesis, deficiencies of methionine, phenylalanine, histidine, and tryptophan were created in dairy cows through provision of a low- 
protein diet and abomasal infusions of essential amino acid mixtures. Deficiency of Met, His, or Phe caused a decrease in milk protein yield, whereas abundance of the signalling protein eukaryotic initiation factor $2 \varepsilon$ demonstrated a protein synthetic regulatory response not previously recognized in bovine mammary tissue. http://dx.doi.org/10.3168/jds.2014-9051.

Effects of a 6-week intraduodenal supplementation with quercetin on energy metabolism and indicators of liver damage in periparturient dairy cows. By Stoldt et al., page 4509. Flavonoids are antioxidative, antilipogenetic, and hepatoprotective compounds found in several plant species. During the periparturient period, dairy cows are metabolically challenged and can develop hepatic disorders. We investigated the effect of daily intraduodenal supplementation of the flavonol quercetin on energy and lipid metabolism during a 6 -wk period with 3 wk prepartum and 3 wk postpartum. The supplementation with quercetin increased plasma flavonoid levels but did not affect energy or lipid metabolism. Postpartum, plasma aspartate aminotransferase activity, a marker of liver damage in ruminants, was $80 \%$ lower with quercetin supplementation, indicating a hepatoprotective effect of systemic quercetin in dairy cows.

http://dx.doi.org/10.3168/jds.2014-9053.

Phenotypic antimicrobial susceptibility and occurrence of selected resistance genes in gram-positive mastitis pathogens isolated from Wisconsin dairy cows. By Ruegg et al., page 4521 . This study determined the antibiotic susceptibility of Staphylococcus spp., Streptococcus spp. and streptococcal-like organisms isolated from cases of clinical mastitis occurring in cows on large Wisconsin dairy herds. Almost all isolates were susceptible to antibiotics (except for pirlimycin) commonly used for intramammary treatment of mastitis, but some resistance to injectable drugs was noted. All Staph. aureus were susceptible to oxacillin. About $40 \%$ of isolates did not carry any of the 4 resistance genes that were assessed. Some pathogens carried multiple resistance genes but the presence of resistance genes did not always correspond with occurrence of phenotypic resistance.

http://dx.doi.org/10.3168/jds.2014-9137.

Definition of prepartum hyperketonemia in dairy goats. By Doré et al., page 4535. The objective of this study was to define blood BHBA levels, which can serve as threshold values during the last month of pregnancy in dairy goats, to identify, earlier, goats that are at high risk of subsequent pregnancy toxemia (PT) and mortality. Hyperketonemia thresholds were found to vary from $\geq 0.4$ to $\geq 1.7 \mathrm{mmol} / \mathrm{L}$ during the last 5 wk of pregnancy. Hyperketonemic goats, at wk 4 before parturition, had the highest odds of subsequent PT and mortality.

http://dx.doi.org/10.3168/jds.2014-9172.

The associations between postpartum serum haptoglobin concentration and metabolic status, calving difficulties, retained fetal membranes, and metritis. By Pohl et al., page 4544. The objective of this study was to evaluate the association between different variables and haptoglobin concentrations after calving. Haptoglobin is an acute phase protein responding to inflammation. Metabolic stress as well as calving difficulties and retained fetal membranes in multiparous cows were associated with haptoglobin at $5 \mathrm{~d}$ in milk. When haptoglobin is used as a diagnostic tool for the detection of cows with acute puerperal metritis, these potential confounders have to be considered although metritis was highly associated with haptoglobin at $5 \mathrm{~d}$ in milk.

http://dx.doi.org/10.3168/jds.2014-9181.

Preferences of lame cows for type of surface and level of social contact in hospital pens. By Jensen et al., page 4552. Lame dairy cows' preferences for surface and level of social contact were investigated in experimental hospital pens with a choice of deep-bedded sand and a rubber surface. Cows preferred to lie in the sand, and they preferred to perform self-grooming on the rubber surface. On both surfaces, cows could choose to be near or away from neighboring animals. Cows preferred to lie and to perform self-grooming near neighboring animals and showed no signs of isolation seeking. The results suggest that access to a deepbedded lying area is important to lame cows.

http://dx.doi.org/10.3168/jds.2014-9203.

Experienced and inexperienced observers achieved relatively high within-observer agreement on video mobility scoring of dairy cows. $B y$ Garcia et al., page 4560. Gait scoring of individual cows is essential for health and welfare assessments, including detection of decreased mobility over time. Meaningful comparison of the cows' gait requires observers who are able to score the same cow equally under the same conditions, at 2 distinct time-points (i.e., within-observer agreement). A total of 102 observers, including cattleexperienced and inexperienced, scored 22 videos in replicates (with 5 gait types). The probability of perfect agreement ranged from 45 to $90 \%$ when considering the effect of gait type. Observers without prior experience obtained up to $60 \%$ perfect agreement, which made them closely on par with experienced observers. http://dx.doi.org/10.3168/jds.2014-9266.

The effect of heat waves on dairy cow mortality. By Vitali et al., page 4572. We studied the effect of heat waves on dairy cow mortality. The risk of death during 
heat waves increases with length of the wave and age of the cows and it is higher in early summer months. In the light of climate scenarios, these results support the implementation of adaptation strategies to ensure animal welfare and limit economic losses in dairy farms during periods of hot weather.

http://dx.doi.org/10.3168/jds.2014-9331.

Insulin response of the glucose and fatty acid metabolism in dry dairy cows across a range of body condition scores. By De Koster et al., page 4580. Insulin is an important hormone in the normal metabolism of dairy cows. In humans, insulin resistance is known to occur in obese individuals. The present research demonstrates a negative association between level of fat accumulation in dairy cows at the end of the dry period and the insulin action at the level of the glucose metabolism. The insulin response at the level of fatty acid metabolism remained unaltered. Additionally, within individual animals, the response of the fatty acid metabolism occurred at lower concentrations of insulin compared with the response of glucose metabolism.

http://dx.doi.org/10.3168/jds.2015-9341.

Milk prolactin response and quarter milk yield after experimental infection with coagulase-negative staphylococci in dairy heifers. By Piccart et al., page 4593. Cows infected with coagulase-negative staphylococci (CNS) produce more milk than uninfected cows. We hypothesized that the lactation hormone prolactin increases in response to a CNS infection. The prolactin increase might then stimulate milk production. Eight mid-lactating Holstein-Friesian heifers were challenged in a split-udder design with 3 different CNS strains. Milk prolactin tended to be higher in the CNS-challenged quarters compared with the control quarters. However, a decline in milk yield was seen in all mammary quarters although it was greater in the infected quarters than in the control quarters.

http://dx.doi.org/10.3168/jds.2015-9349.

Short communication: Protease activity measurement in milk as a diagnostic test for clinical mastitis in dairy cows. By Koop et al., page 4613. In automated milking systems, accurate detection of clinical mastitis in an automated way is crucial. This study describes a new diagnostic approach for clinical mastitis based on protease activity measurement, which may present an addition to the currently available mastitis diagnostics in automated milking systems.

http://dx.doi.org/10.3168/jds.2014-8746.

Effects of different model diets on milk composition and expression of genes related to fatty acid synthesis in the mammary gland of lactating dairy goats. By Zhang et al., page 4619.
This study determined the effects of different roughage diets on milk fat synthesis in the mammary gland of dairy goats. Goats fed a high-quality roughage (HQR) diet had higher milk fat and milk protein contents and tended to a have higher milk fat yield when compared with those fed a low-quality roughage diet (LQR). Milk fat of C18:3n-3, mammary balance of total fatty acids, and the expression of lipoprotein lipase and stearoyl CoA desaturase were higher in goats fed with HQR, and the clearance rate of total fatty acids was lower in goats fed HQR compared with those fed LQR.

http://dx.doi.org/10.3168/jds.2013-7097.

Effect of feeding calcareous marine algae to Holstein cows prepartum or postpartum on serum metabolites and performance. By Wu et al., page 4629. Calcareous marine algae has been suggested to be suitable as a dietary calcium supplement with buffering potential, but limited data are available on its effect on production. The objective of this trial was to evaluate the effects of supplemental calcareous marine algae beginning either prepartum or after calving on the performance of lactating dairy cows. No differences were observed in intake or serum metabolites among treatments throughout the trial. Milk protein yield was higher for cows fed calcareous marine algae prepartum compared with control. No differences were observed in performance of cows fed diets supplemented with either calcareous marine algae or sodium bicarbonate postpartum. Results of this trial suggest that calcareous marine algae may be used in diets fed to dairy cows both prepartum and postpartum.

http://dx.doi.org/10.3168/jds.2014-8711.

Effect of colostrum heat treatment and bacterial population on immunoglobulin G absorption and health of neonatal calves. By Gelsinger et al., page 4640. Bull calves $(\mathrm{n}=104)$ received $3.78 \mathrm{~L}$ of unheated or heat-treated colostrum of low or high bacteria content, and blood was collected $48 \mathrm{~h}$ after birth for immunoglobulin ( $\mathrm{Ig}) \mathrm{G}$ and total protein analysis. Health scores were assigned daily for $7 \mathrm{~d}$ after birth. High bacteria content reduced total protein, plasma $\mathrm{IgG}$, and apparent efficiency of IgG absorption. Heat treatment tended to improve IgG absorption as measured by ELISA, and calves that received heat-treated colostrum with low bacteria content tended to experience fewer scour days in the first week of life.

http://dx.doi.org/10.3168/jds.2014-8790.

Using wireless rumen sensors for evaluating the effects of diet and ambient temperature in nonlactating dairy goats. By Castro-Costa et al., page 4646. Wireless boluses were inserted into the rumen of dairy goats to evaluate the effects of diet and environment on ruminal temperature and $\mathrm{pH}$. In experiment 1, 8 does fed 30 or $70 \%$ concentrate showed marked 
differences in $\mathrm{pH}$ but not in rumen temperature, which decreased by drinking cold water. In experiment 2,8 does fed with a $50 \%$ concentrate diet were submitted to thermal neutral and heat-stress conditions. Rumen temperature was higher in heat-stressed than in thermal neutral does. Despite the same diet and intake, rumen $\mathrm{pH}$ of heat-stressed does was lower than in thermal neutral does. Wireless sensors proved to be sensitive enough for the continuous monitoring of rumen environment in goats.

http://dx.doi.org/10.3168/jds.2014-8819.

Effect of adding cofactors to exogenous fibrolytic enzymes on preingestive hydrolysis, in vitro digestibility, and fermentation of bermudagrass haylage. By Romero et al., page 4659. Warm-season grasses, such as bermudagrass, are an essential feed source for the dairy industry in the southeastern United States but their low quality can limit the productivity of dairy cattle. Attempts to use fiber-digesting enzymes to improve the quality of these grasses have yielded contrasting results. Cofactors are metal ions required by most enzymes for proper function. This study showed that adding cofactors to enzymes can result in an increase, decrease, or no change in the digestibility of bermudagrass. The outcome depends on the specific enzyme-cofactor combination and the cofactor concentration.

http://dx.doi.org/10.3168/jds.2014-8849.

The effects of feeding rations that differ in neutral detergent fiber and starch concentration within a day on production, feeding behavior, total-tract digestibility, and plasma metabolites and hormones in dairy cows. By Rottman et al., page 4673. There is a daily pattern of feed intake and milk synthesis in the dairy cow, and feeding a single total mixed ration over the day may not synchronize ruminal fermentation, nutrient absorption, and milk synthesis. Our hypothesis was that feeding a high forage diet during the high intake period of the day and a low forage diet during the low intake overnight period of the day would stabilize rumen fermentation, nutrient absorption, and the availability of nutrients for milk synthesis. Feeding diets that differed in neutral detergent fiber and starch concentration at different times of the day modified feeding behavior, milk fat yield, and daily intake, but had no effect on total-tract digestibility. Feeding multiple rations over the day provides an opportunity to modify animal behavior and physiology, but both the timing of feeding and composition of the diet must be considered.

http://dx.doi.org/10.3168/jds.2014-8859.

The effects of feeding rations that differ in neutral detergent fiber and starch concentration within a day on rumen digesta nutrient concentration, $\mathrm{pH}$, and fermentation products in dairy cows. By Ying et al., page 4685. The object of this study was to determine the effect of feeding a highforage diet during the high-intake period of the day and a low-forage diet during the low-intake overnight period on key rumen responses. Feeding diets that differed in neutral detergent fiber and starch concentration at different times of the day modified rumen neutral detergent fiber and starch concentration and pool size after feeding. A large amount of feed consumed in the evening resulted in a shift in peak amounts of acetate, propionate, and biohydrogenation intermediates after this feeding. Feeding multiple rations over the day to improve rumen fermentation must consider the effect on feeding behavior.

http://dx.doi.org/10.3168/jds.2014-8873.

Milk production responses to a change in dietary starch concentration vary by production level in dairy cattle. By Boerman et al., page 4698. In this study, responses to diets differing in starch concentration were evaluated for lactating dairy cows across a wide range of milk production. The high-starch diet increased dry matter intake and dry matter digestibility compared with the low-starch diet. Higher-producing cows responded more negatively to a reduction in starch concentration than did low-producing cows, as low-producing cows were able to maintain milk production on the low-starch diet. http://dx.doi.org/10.3168/jds.2014-8999.

Relationships between circulating plasma concentrations and duodenal flows of essential amino acids in lactating dairy cows. By Patton et al., page $470 \%$. Globally, approximately $25 \%$ of dietary $\mathrm{N}$ is converted to milk protein in dairy cows. A more accurate definition of essential amino acid (EAA) requirements might make it possible to increase this efficiency, increasing economic gain and reducing environmental nitrogen pollution. Plasma free EAA are the direct precursors of milk protein. It has been suggested that changes in plasma EAA concentration can reflect EAA requirements. This was not confirmed by our study, which showed that plasma EAA reflect duodenal EAA flow but not requirements.

http://dx.doi.org/10.3168/jds.2014-9000.

Residual feed intake is repeatable for lactating Holstein dairy cows fed high- and low-starch diets. By Potts et al., page 4735. Residual feed intake is being considered as a selection criterion in dairy cattle breeding to improve feed efficiency. In this study, lactating cows were fed diets that differed markedly in starch content in cross-over design experiments. Residual feed intake was determined for individual cows when fed high- and low-starch diets. Residual feed intake was highly repeatable across these diets, indicating that 
cows that are most efficient on one diet should be most efficient on other diets as well.

http://dx.doi.org/10.3168/jds.2014-9019.

Short- and long-term effects of forage supplementation of calves during the preweaning period on performance, reproduction, and milk yield at first lactation. By Castells et al., page 4748 . Recently, enhancing calf growth during the preweaning period has been associated with long-term effects during the adulthood. This study evaluated the effects of improving growth of calves during the preweaning period by offering forage. Although growth was improved early in life, improvements on reproduction or milk yield were not observed later in life. However, data obtained in this study indicated a positive relationship between growth rate early in life and future energycorrected milk during the first lactation.

http://dx.doi.org/10.3168/jds.2014-9025.

Preliminary validation of a calf-side test for diagnosis of failure of transfer of passive immunity in dairy calves. By Elsohaby and Keefe, page 4754. Measurement of bovine serum immunoglobulin $\mathrm{G}$ ( $\mathrm{IgG}$ ) concentration is critical for early and accurate diagnosis of failure of transfer of passive immunity in dairy calves. As a consequence, there is need for simple, economic, rapid, and accurate diagnostic assays for IgG. In the dairy industry, multiple methods for measurement of IgG level have been evaluated, each with particular advantages and disadvantages. This study investigated the utility of an initial version of a calfside test for diagnosis of failure of transfer of passive immunity in dairy calves.

http://dx.doi.org/10.3168/jds.2014-9027.

Substitution of common concentrates with by-products modulated ruminal fermentation, nutrient degradation, and microbial community composition in vitro. By Ertl et al., page 4762. A rumen simulation technique was used to investigate the effects of substituting common concentrates with a mixture of by-products at forage-to-concentrate ratios of $75: 25$ or 50:50. We found that by-products have the potential to adequately substitute common concentrates with regards to their effects on rumen fermentation profile, nutrient degradation, and microbial abundance. The results of this study help us further understand ruminal fermentation patterns of by-products when they completely substitute common concentrates. http://dx.doi.org/10.3168/jds.2014-9063.

Performance, bioenergetic status, and indicators of oxidative stress of environmentally heatloaded Holstein cows in response to diets inducing milk fat depression. By Kargar et al., page 4772. This experiment investigated the effects of feeding diets (interaction between barley grain vs. corn grain and fish oil vs. soybean oil) inducing milk fat depression on performance, energy partitioning, and antioxidant status of heat-loaded Holstein cows. Fish oil (but not type of grain) decreased dry matter intake and milk yield. Elevated plasma markers of liver function and an increase in plasma lipoperoxidation, due to impaired antioxidant status, in cows fed fish oil were associated with liver dysfunction and lowered performance of the cows. Although energy balance remained unchanged among treatments, feeding fish oil slightly partitioned energy towards body mass at the expense of milk yield, regardless of type of grain used.

http://dx.doi.org/10.3168/jds.2014-9100.

Incremental amounts of ground flaxseed decrease milk yield but increase n-3 fatty acids and conjugated linoleic acids in dairy cows fed high-forage diets. By Resende et al., page 4785. Effect of ground flaxseed on milk yield and fatty acids profile in dairy cows. Flaxseed is one of the richest source of the n-3 fatty acid (FA) $\alpha$-linolenic acid. Previous studies showed that feeding flaxseed to dairy cows increased milk n-3 FA and conjugated linoleic acids (CLA), which are FA with potential human health benefits. We aimed to investigate the effect of flaxseed on milk yield and milk FA profile in dairy cows fed high-forage diets. Feed intake and production of milk and milk components (i.e., fat and protein) decreased with flaxseed supplementation, whereas n-3 FA and CLA increased substantially in milk fat.

http://dx.doi.org/10.3168/jds.2014-9115.

Providing supplementary milk to suckling dairy calves improves performance at separation and weaning. By Johnsen et al., page 4800. For suckling calves, separation and weaning are major welfare challenges. In this study, we provided suckling calves with access to a milk feeder that calves could continue to use after separation from the cow. Calves with access to the supplementary milk supply gained more weight at separation and during weaning. Providing access to an alternative milk supply can improve performance in suckling systems.

http://dx.doi.org/10.3168/jds.2014-9128.

Tomato seeds as a novel byproduct feed for lactating dairy cows. By Cassinerio et al., page 4811. Whole tomato seeds were fed to lactating dairy cows, with the lipid from tomato seeds replacing the lipid from whole cottonseed. Dry matter intake, milk yield, and concentrations and yields of protein and lactose did not differ. However, milk fat concentration decreased as whole tomato seeds replaced whole cottonseed. Wholetract apparent digestibility of dry matter and ash-free neutral detergent fiber did not differ, but digestibility of total fatty acids and crude protein decreased with 
tomato seeds. Feeding tomato seeds to dairy cows is a method to deal with a by-product of tomato processing. http://dx.doi.org/10.3168/jds.2014-9121.

Postruminal synthesis modifies the odd- and branched-chain fatty acid profile from the duodenum to milk. By Vlaeminck et al., page 4829. Odd- and branched-chain fatty acids (OBCFA) have been shown to be potential markers for rumen function. The potential of milk OBCFA as a biomarker implies that the rumen or duodenal OBCFA profile is reflected in milk. However, we showed greater milk secretion of some OBCFA compared with duodenal flows, which suggests the occurrence of postruminal synthesis, such as de novo synthesis, desaturation, and elongation. The postruminal modification of the OBCFA profile might hamper the application of OBCFA as diagnostic tool of rumen function.

http://dx.doi.org/10.3168/jds.2014-9207.

Effect of including canola meal and supplemental iodine in diets of dairy cows on short-term changes in iodine concentrations in milk. By Weiss et al., page 4841. Iodine is a required nutrient for dairy cows. However, feeding excess iodine can result in high iodine concentrations in milk, which could cause human health problems when the milk is consumed. However, data are available showing that feeding iodine above requirement may improve hoof health of the cow. In this experiment, we determined that feeding canola meal instead of soybean meal reduced iodine concentrations in milk. As little as $3.9 \%$ canola meal in the diet reduced milk iodine but $13.9 \%$ canola meal was required to keep milk iodine concentrations in the acceptable range when diets were supplemented with 2 $\mathrm{mg} / \mathrm{kg}$ of iodine.

http://dx.doi.org/10.3168/jds.2014-9209.

Effects of corn silage particle size, supplemental hay, and forage-to-concentrate ratio on rumen $\mathrm{pH}$, feed preference, and milk fat profile of dairy cattle. By Kmicikewycz et al., page 4850. High-concentrate diets can produce subacute ruminal acidosis (SARA) and change ruminal fermentation and mammary secretion of fatty acids. In this study, SARA was induced by feeding a 50\% forage, $50 \%$ concentrate diet. During SARA, increasing corn silage particle size and adding supplemental hay to diets containing long corn silage increased the acetate-to-propionate ratio in the rumen. Adding supplemental hay to rations based on long or short corn silage prevented acidosis when cows were challenged with SARA. Feeding longer corn silage in the total mixed ration or supplementing hay during a SARA insult increased rumen $\mathrm{pH}$, acetate-topropionate ratio, and rate of recovery.

http://dx.doi.org/10.3168/jds.2014-9249.
Effects of conditioning temperature and time during the pelleting process on feed molecular structure, pellet durability index, and metabolic features of co-products from bio-oil processing in dairy cows. By Huang et al., page 4869. This study aimed to systematically investigate effects of temperature and time of conditioning during the pelleting process on pellet durability index (PDI), processinginduced changes on protein molecular structure, metabolic features, and nutrient utilization and availability of protein and carbohydrate in dairy cattle.

http://dx.doi.org/10.3168/jds.2014-9290.

Inclusion of tallow and soybean oil to calf starters fed to dairy calves from birth to four months of age on calf performance and digestion. By Hill et al., page 4882. Inclusion of $2 \%$ tallow or soybean oil in starters fed to dairy calves up to 4 mo of age did not increase metabolizable energy intake, average daily gain (ADG), or structural growth. Soybean oil reduced digestion during wk 7 of life. Soybean oil reduced ADG before $8 \mathrm{wk}$ of age and reduced ADG and structural growth to 4 mo of age. Tallow reduced ADG and tended to reduce structural growth between 2 and 4 mo of age. Tallow and soybean oil inclusion at $2 \%$ of the starter was not advantageous for calf growth before 4 mo of age.

http://dx.doi.org/10.3168/jds.2015-9376.

Effect of feed-related farm characteristics on relative values of genetic traits in dairy cows to reduce greenhouse gas emissions along the chain. By Van Middelaar et al., page 4889. The greenhouse gas (GHG) value of a genetic trait represents the effect of genetic improvement on GHG emissions along the chain, and it provides insight into the relative importance of individual traits to reduce emissions. The GHG values of milk yield and longevity were calculated based on maximizing labor income and minimizing GHG, respectively, and for an efficient and less efficient farm. When maximizing income, the importance of milk yield relative to longevity depends on farm efficiency. When minimizing GHG, both traits were equally important on each level of efficiency. http://dx.doi.org/10.3168/jds.2014-8310.

Inbreeding and crossbreeding parameters for production and fertility traits in Holstein, Montbéliarde, and Normande cows. By Dezetter et al., page 4904. Breed differences and nonadditive genetic effects for milk production traits, somatic cell score (SCS), conception rate (CR), and days to first service (DFS) were estimated for Holstein $\times$ Montbéliarde and Holstein $\times$ Normande crossbreds. The Holstein breed was genetically superior for production and inferior for fertility traits compared with the other 
2 breeds. Inbreeding depression caused loss of yields, a small increase in SCS and DFS, and a decrease of CR. Favorable heterosis effects were found for all traits. However, recombination loss estimates, although not significant, suggested that part of the $\mathrm{F}_{1}$ heterosis was lost in backcross cows.

http://dx.doi.org/10.3168/jds.2014-8386.

Genetic parameters of cheese yield and curd nutrient recovery or whey loss traits predicted using Fourier-transform infrared spectroscopy of samples collected during milk recording on Holstein, Brown Swiss, and Simmental dairy cows. By Cecchinato et al., page 4914. Cheese yield and cheese nutrient recovery or whey loss are the most important technological parameters in the dairy industry. Here, the ability of Fourier-transform infrared (FTIR) calibration of milk spectra to predict cheese yield and nutrient recovery traits was tested on population-level samples collected during the milk recording of Holstein, Brown Swiss and Simmental dairy cows. The FTIRpredicted cheese traits exhibited exploitable levels of genetic variation, with heritability estimates varying from moderately low (daily cheese production) to high (protein recovery in curd/loss in whey). Thus, FTIR predictions have the potential to be used for the inexpensive selection of cheese yield-related traits in dairy populations for which spectra are routinely obtained from individual milk samples.

http://dx.doi.org/10.3168/jds.2014-8599.

Information from later lactations improves accuracy of genomic predictions of fertility-related disorders in Norwegian Red. By Haugaard et al., page 4928. The aim of this study was to examine whether including information from later lactations improves accuracy in prediction of genomic breeding values for fertility-related disorders in Norwegian Red. Health records from $>6$ million lactations of 2.4 million cows were analyzed. Genomic breeding values for cystic ovaries, metritis, retained placenta, and silent heat were predicted based on first lactation only and by using information from lactations 1 to 5 . Including later lactations improved accuracy of genomic breeding values for cystic ovaries, retained placenta and silent heat, whereas no obvious advantage in accuracy was found for metritis.

http://dx.doi.org/10.3168/jds.2014-8988.

Using a family-based structure to detect the effects of genomic inbreeding on embryo viability in Holstein cattle. By Bjelland et al., page 4934. Genomic inbreeding measures were simulated from sire-dam mating pairs and compared with the genomic inbreeding of actual progeny from these matings. As no differences between the simulated and actual progeny were detected, no detrimental effects of increases in embryonic inbreeding could be identified. Comparisons between genomic inbreeding measures of full siblings were also compared and displayed moderate correlations.

http://dx.doi.org/10.3168/jds.2014-9014.

Genomic evaluation of a relatively small dairy cattle population by combination with a larger population. By Weller et al., page 4945. We investigated the accuracy of genomic evaluations for Israeli Holsteins, a small dairy cattle population, via joint evaluation with Dutch Holsteins, a much larger population. Correlations of 2014 evaluations with genomic evaluations based on 2009 data were higher than the correlations for parent averages for all traits. Milk production traits were biased upward for both genomic evaluations and parent averages. Bias was greater for parent averages. Genomic evaluations for bulls with high 2014 evaluations were less biased. The difference in mean current evaluations between bulls born between 2007 and 2008 selected by genomic evaluations and parent average was $7 \%$ of annual gain.

http://dx.doi.org/10.3168/jds.2014-9086.

Genetic analysis of heat stress effects on yield traits, udder health, and fatty acids of Walloon Holstein cows. By Hammami et al., page 4956. Adaptation of dairy cattle to extreme weather fluctuations, a proxy for future climate change, is of increased interest worldwide, especially in temperate regions. This study investigated the phenotypic and genetic variation of conventional and novel Holstein milk composition traits under weather conditions in the Walloon region of Belgium. Most traits had phenotypic and genetic declines as temperature-humidity index increased. Content of C18:1 cis-9 in milk was the most sensitive trait to hot conditions and its changes under hot conditions could be used as a milk-based biomarker to assess and select for heat tolerance in dairy cattle.

http://dx.doi.org/10.3168/jds.2014-9148.

Strategies for single nucleotide polymorphism (SNP) genotyping to enhance genotype imputation in Gyr (Bos indicus) dairy cattle: Comparison of commercially available SNP chips. $B y$ Boison et al., page 4969. We studied genotype imputation in Gyr (Bos indicus) dairy cattle by comparing different single nucleotide polymorphism (SNP) panels and imputation algorithms. Three genotyping chips50K, GeneSeek GGP-75Ki, and HD-777K - were used as high-density SNP panels (HDP). The SNP chips 3K, 7K, GeneSeek SGGP-20Ki, 50K, and GGP-75Ki were used as alow-density SNP panel depending on the HDP. Two imputation software packages - Beagle and FImpute - were studied. The HD-777K and GGP-75Ki chips were the best HDP. Imputing from SGGP-20Ki to HD-777K was as accurate as imputing from $50 \mathrm{~K}$ 
to HD-777K. When 50K was imputed to GGP-75Ki, imputation accuracy was poor. FImpute was the most accurate software package.

http://dx.doi.org/10.3168/jds.2014-9213.

Short communication: Genetic analysis for fertility traits of heifers and cows from smallholder dairy farms in a tropical environment. By Buaban et al., page 4990. As a case study, fertility traits of Thai dairy cattle were analyzed using artifical insemination data from the national recording scheme. Reproductive performances in different parities were considered as different traits. Estimated heritabilities of most reproductive traits were 0.04 or less except age at first service and age at first calving. Genetic correlations between different fertility traits within parity indicated that selection for cows with high conception rate could lead to shorten days open (DO) and calving interval (CI), as well as days from calving to first service (DTFS). Conception at first service (FSC) and number of services per conception (NSPC) could be good indicators for heifer and cow fertility and could be complemented by other traits that were considered genetically to be different traits, such as DTFS and days between first and last service (DFLS) in terms of a fertility index. This would enable efficient selection for better reproductive performance. Heifer and cow fertility should be considered as different traits. http://dx.doi.org/10.3168/jds.2014-8866.
Short communication: Reliability of single-step genomic BLUP breeding values by multi-trait test-day model analysis. By Bauer et al., page 4999. Molecular genetic information improves reliability of prediction of genetic merit of farm animals. We developed a method to approximate reliability of breeding values for milk production traits from routine test-day evaluation by multi-trait single-step analysis for nationwide phenotypic and genomic data. Genetic evaluation results are routinely published for practical use by cattle breeders in the Czech Republic.

http://dx.doi.org/10.3168/jds.2015-9371.

Partitioning variation in nutrient composition data of common feeds and mixed diets on commercial dairy farms. By St-Pierre and Weiss, page 5004. Samples of common feeds and mixed diets were taken on commercial dairy farms in a manner that allowed partitioning sources of variation in feed composition. We determined that sampling was the major source of variation in the composition of silages within a farm over a short period. Over a 12-mo period, true month-to-month variation was the greatest source of variation but sampling variance was still substantial. This project shows that substantial uncertainty exists when single samples of forages and common feeds are used. Data from multiple samples should be used when formulating diets.

http://dx.doi.org/10.3168/jds.2015-9431. 